\title{
Characterization of Particles in Cream Cheese
}

\author{
M. R. Sainani, H. K. Vyas, and P. S. Tong \\ Dairy Products Technology Center, \\ Cal Poly State University, \\ San Luis Obispo 93405
}

\begin{abstract}
Cream cheese is used as a spread and as an ingredient in many food applications. A gritty or grainy mouthfeel is an undesirable textural defect that occurs in cream cheese. However, the factors that cause the textural defect are not well understood. The objectives of this study were to isolate and characterize particles from cream cheese and to study the effect of particles on cheese texture. Particles were isolated by washing cream cheese with water first at $25^{\circ} \mathrm{C}$ and then at $50^{\circ} \mathrm{C}$ repeatedly 4 to 5 times. The size of these particles was determined using a particle size analyzer. The particles as well as the original cheeses were analyzed for moisture, fat, protein, ash, and lactose. The particle size ranged of 0.04 to $850 \mu \mathrm{m}$. It was found that isolated particles were significantly higher in protein content as compared with the whole cheese. To study the effect on the cheese texture, particles were added at 5, 15, and $25 \%$ (wt/wt) levels to smooth cream cheese, and a sensory ranking test was done on the samples. Isolated particles were further separated into 2 size classes of 2.5 to $150 \mu \mathrm{m}$ and $\geq 150 \mu \mathrm{m}$. These particles were then mixed with smooth cream cheese at 16 and 29\% (wt/ wt), and a sensory test was conducted on these samples. Smooth cream cheese with only $5 \%$ (wt/wt) added particles was perceived as significantly grittier than the control sample. This experiment also revealed that the perceived grittiness increased with increase in amount and size of particles.
\end{abstract}

(Key words: grittiness, cream cheese)

Abbreviation key: SEM = scanning electron microscopy, $\mathbf{T E M}=$ transmission electron microscopy.

\section{INTRODUCTION}

Cream cheese has soft, rich, mildly acid flavor and a smooth consistency. It is made from cream or from a mixture of cream and milk or skim milk. Traditionally,

Received March 12, 2003.

Accepted April 14, 2004.

Corresponding author: P. S. Tong; email: ptong@calpoly.edu. cream cheese mix is pasteurized, homogenized, inoculated with lactic culture, and held at $23^{\circ} \mathrm{C}$ until it attains a $\mathrm{pH}$ of approximately 4.6. The curd is heated to 52 to $63^{\circ} \mathrm{C}$, and stabilizers, emulsifiers and salt are added. This mixture is homogenized and is packed either cold or hot. In 2000, the production of cream cheese in the United States was about 312 million $\mathrm{kg}$, and per capita consumption was $1.10 \mathrm{~kg}$ (IDFA, 2001).

Typical cream cheese has a smooth texture and is somewhat spreadable at refrigerator temperatures. Cream cheese is used as a spread and as an ingredient in baked goods, desserts, and other food products. In these applications, gritty or grainy cheese texture is an undesirable textural defect. Modler et al. (1989) reported the formation of small hard particles when the cheese was heated at 44 to $63^{\circ} \mathrm{C}$ for $30 \mathrm{~min}$. These small hard particles were detected by sensory evaluation and also by viewing the cheese under a light microscope. According to Kalab et al. (1975), grittiness in cream cheese may be due to the interactions between protein and various ingredients such as stabilizers and other thickening agents. Kalab et al. (1981) observed a corpuscular microstructure in the finished product when the curd was stirred and homogenized during manufacture. Such corpuscular (particulate) structure was seemingly responsible for the spreadability and smoothness of creamed cheeses (Kalab and Modler, 1985).

Several studies have been reported on the microstructure of different kinds of cream cheese (Kalab et al., 1981; Kalab and Modler, 1985; Xiong and Kinsella, 1991; Sanchez et al., 1996). Kalab and Modler (1985) studied the development of microstructure at each individual stage of cream cheese manufacturing from cultured cream (58\% fat) and Queso Blanco curd. They found that the microstructure of the cheese was related to the temperature of coagulation; the microstructure was granular, and the grain size decreased from 5 to $0.5 \mu \mathrm{m}$ with the decrease in coagulation temperature from 98 to $\sim 76.5^{\circ} \mathrm{C}$. Harwalkar and Kalab $(1980,1981)$ observed a characteristic core-and-lining ultra structure of the casein matrix in the curd using scanning electron microscopy (SEM) and transmission electron microscopy (TEM) techniques. The nature of this structure depended on the temperature of coagulation. 
In case of double cream cheese, curd originates from a mixture that mainly contains emulsified milk fat and milk proteins. Different heat treatments and the homogenization applied to the mixture leads to the formation of milk fat globules mainly surrounded by a stabilizing protein layer (casein and heat-denatured whey protein). These pseudo-protein particles participate in a polymerization mechanism involving caseins such as acid coagulation (Xiong and Kionsella, 1991). Sanchez et al. (1996) reported that double cream cheese is mainly structured by compact casein-milk fat globules aggregates defining large whey containing areas as well as partly coalesced milk fat globules.

High heat treatment of milk is one of the most important processing parameters affecting the texture of acid milk gels such yogurt, Quarg, etc. (Mulvihill and Grufferty, 1995). Heating of milk above $80^{\circ} \mathrm{C}$ denatures whey proteins that then associate with casein micelles (Mulvihill and Donovan, 1987). $\kappa$-casein and $\beta$-lactoglobulin are involved in the interaction between casein micelles and heat-denatured whey proteins via intermolecular disulphide bond formation (Singh and Creamer, 1992).

When the heated milk is acidified, the denatured whey proteins in the serum, as well as those associated with the casein micelles, become susceptible to aggregation, as the net repulsive charge on the protein is reduced (Zhu and Damodaran, 1994). The denatured whey protein associated with the casein micelles participate in gelation and could act as a bridging material by interacting with other denatured whey proteins associated with the casein micelles. This would hinder the close approach of other casein particles, thus preventing the formation of a dense cluster of casein particles (Lucey et al., 1998).

Modler et al. (1989) studied the grittiness of pasteurized cheese spread by a microscopic examination of the gritty particles using fluorescence microscopy, SEM, and TEM. They reported that the development of grittiness in the product was related to the heat treatment of milk. Examination of the gritty particles indicated that they consisted of compacted protein and they were amorphous and contained no crystalline structures. Modler et al. (1990) reported that grittiness in hotpacked cream cheese could not be prevented by homogenization, use of stabilizers, replacement of bacterial starter cultures, or reduction of temperature during hot packing.

Despite these studies, the specific cause of graininess and how to control graininess in cream cheese is not understood well; specifically, the impact of particle size on the perceived grittiness had not been studied. Therefore, the aim of this study was to isolate and characterize the particles in cream cheese and to determine the

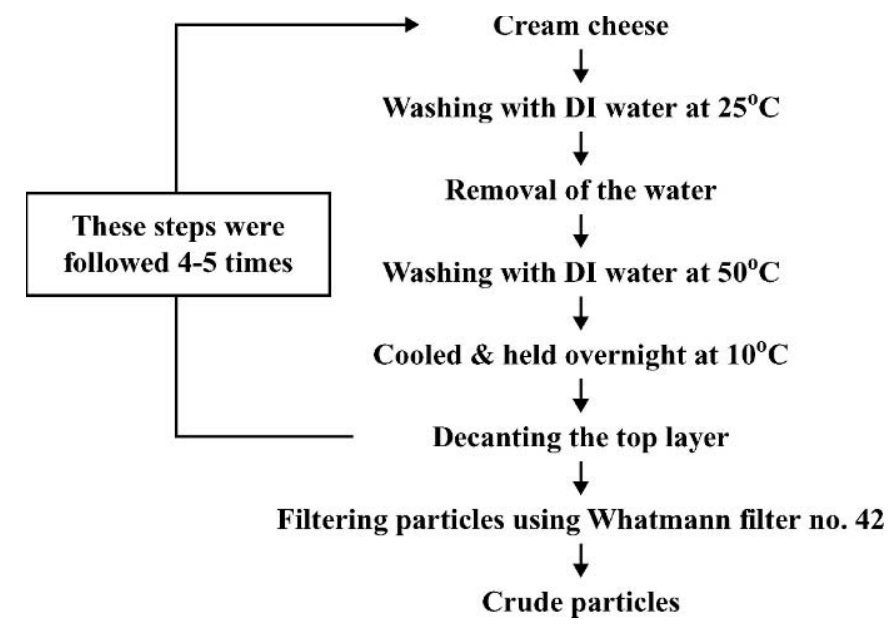

Figure 1. Flow diagram for isolation of crude particles from gritty cream cheese. DI = deionized.

importance of particles in the texture and perceived grittiness in the cheese.

\section{MATERIALS AND METHODS}

\section{Cream Cheese}

Three different types of cream cheeses were studied: A) cream cheese with induced grittiness, B) gritty cheese obtained from a commercial manufacturer, and C) smooth commercial cream cheese.

Cream cheese with induced grittiness was manufactured in pilot plant. Steps for manufacture were as follows. First, whole milk, cream, and skim milk powder $(\sim 27 \mathrm{~g} / \mathrm{kg}$ of the total mix) were blended to make a $12 \%$ fat, $22 \%$ TS mixture. Second, the mix was pasteurized at $72^{\circ} \mathrm{C}$ for $15 \mathrm{~s}$ then homogenized (10.35 $\mathrm{MPa}$ on first stage and 3.5 MPa on second stage). The starter culture (Flora Danica Normal from Chr Hansen, Milwaukee, WI) was then added $\left(0.044 \mathrm{~g} / \mathrm{kg}\right.$ of milk) at $23^{\circ} \mathrm{C}$ and incubated for 14 to $16 \mathrm{~h}$ until the $\mathrm{pH}$ reached 4.55 to 4.6. The curd was then broken by stirring and then was heated to $55^{\circ} \mathrm{C}$ for $30 \mathrm{~min}$. The heated curd was filled into muslin bags and pressed until the curd TS was $45 \%$. Finally, the product was filled in the plastic tubs and stored at refrigerated condition.

Cheeses B and C were obtained from commercial manufacturers. In case of Cheese B, the product was not added with stabilizers and was not homogenized before packaging; for Cheese $\mathrm{C}$, the product was added with stabilizers or gums and was also homogenized before packaging.

\section{Separation and Fractionation of the Particles}

Particles were isolated from the $400 \mathrm{~g}$ of gritty cream cheeses (pilot scale and commercial) as shown in Figure 


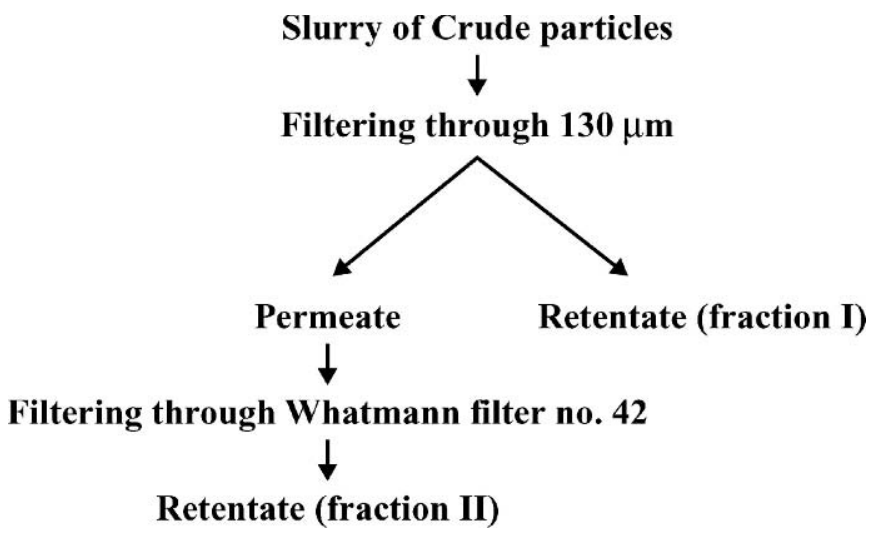

Figure 2. Flow diagram for fractionation of the crude particles to Fraction I and II.

1. The cheese was washed with $\sim 800 \mathrm{~mL}$ of deionized water first at $25^{\circ} \mathrm{C}$. The water was decanted, and then the cheese was washed at $50^{\circ} \mathrm{C}$ with deionized water. The suspension was then cooled and held overnight at $10^{\circ} \mathrm{C}$, and the top fat layer was decanted. These steps (washing at 25 and $50^{\circ} \mathrm{C}$ ) were repeated 4 to 5 times to obtain good isolation of the particles. The suspensions were then vacuum-filtered through Whatman filter no. 42. The particles isolated were called crude particles.

The crude particles were further separated into 2 size classes 1) 2.5 to $150 \mu \mathrm{m}$ and 2) $\geq 150 \mu \mathrm{m}$ using filters (Figure 2). This was accomplished by making the slurry of the isolated particles with deionized water and filtering it through a USA standard testing sieve (no. 100; Fisher Scientific Co., Texas) with a mesh size of 150 $\mu \mathrm{m}$. The particles were washed continuously with water to get good separation. The retained particles (Fraction I) were $\geq 150 \mu \mathrm{m}$. The filterate, which consisted of particles $<150 \mu \mathrm{m}$, was refiltered using Whatman filter no. 42. The retained particles were called Fraction II.

\section{Analysis of Cheese and Particles}

The cheese and the particles were analyzed for TS (990.20), fat (989.04), protein (991.20), and ash (935.42) using standard methods (AOAC, 2000). Lactose was determined by difference for the pilot scale cheese and particles and by enzymatic kit (Kleyn and Trout, 1984) in case of commercial cheeses and particles isolated from them.

The protein profile of the cheese and the particles were determined using a 15\% SDS-PAGE gel with a thickness of $0.75 \mathrm{~mm}$. Samples were prepared according to the method described by Gores (1993). The samples were prepared in reducing (mercaptoethanol was used for breaking the disulphide bonds in the protein) and denaturing (SDS was used for complete unfolding of the native protein structure) conditions, and $20 \mu \mathrm{L}$ of prepared sample (protein concentration of $0.5 \mathrm{mg} / \mathrm{mL}$ ) was loaded per well. Electrophoresis of gels was carried out at $80 \mathrm{~V}$ for $15 \mathrm{~min}$ and at $120 \mathrm{~V}$ for the rest of the time. The time for mini gels was 90 to $120 \mathrm{~min}$. Gels were stained for 14 to $16 \mathrm{~h}$ using Brilliant blue R concentrate (Sigma Chemical Co., St. Louis, MO) and destained for 2 to $3 \mathrm{~h}$ with continuous gentle shaking. Different fractions of the proteins were quantified using imaging densitometer (model GS-700; Bio-Rad, Hercules, CA and molecular analyst software (version 2.1; Bio-Rad).

The size distribution of the particles in suspension was estimated using a fluid module of Coulter LS230 particle size analyzer (Coulter Corp., Miami, FL). Particle size analysis was carried out on Fraction I as well as on Fraction II. Particle size was measured at obscuration value $\geq 8 \%$ and polarization intensity differential scattering value between 45 and 55\%. The pump was run at $40 \%$ speed, and the test run length was $60 \mathrm{~s}$.

Scanning electron microscopy was done on gritty cheese manufactured at pilot scale and on the commercial smooth cheese. Cheese samples put in a petri dish (approximately $1 \times 1 \times 10 \mathrm{~mm}$ ) were fixed in $2 \%$ glutaraldehyde solution for $1 \mathrm{~h}$ at room temperature $\left(22^{\circ} \mathrm{C}\right)$. The glutaraldehyde solution was then changed, and the samples were stored in new glutaraldehyde solution for $2 \mathrm{~d}$ at $4^{\circ} \mathrm{C}$. After refrigerated storage, the samples were processed according to McManus et al. (1993). Samples were transferred to liquid nitrogen and cryofractured perpendicular to their long axis. They were then dehydrated in a graded ethanol series followed by fat extraction with Freon 113 (Electron Microscopy Sciences, Fort Washington, PA). After overnight storage in Freon 113 at $4^{\circ} \mathrm{C}$, the samples were rehydrated by reversing the graded ethanol series and washed with a $0.1 \mathrm{M}$ sodium cacodylate buffer ( $\mathrm{pH}$ 7.2) (Acros, NJ). The samples were then postfixed for $2 \mathrm{~h}$ with a solution containing $1 \% \mathrm{OsO}_{4}$ (Electron Microscopy Sciences) and 1.5\% $\mathrm{K}_{4} \mathrm{Fe}(\mathrm{CN})_{6} \cdot 3 \mathrm{H}_{2} \mathrm{O}$ (Acros). This solution was replaced by a $2 \%$ tannic acid (Acros) solution in cacodylate buffer, and the samples were left for $3 \mathrm{~h}$ at room temperature. The tannic acid solution was then replaced with the mentioned solution of osmium tetroxide and potassium ferrocyanate, and samples were left for $4 \mathrm{~h}$. This solution was later replaced with an aqueous solution of $1 \%$ hydroquinone (Acros), and samples were left overnight. After the heavy metal impregnation, the samples were washed with distilled water, dehydrated in a graded ethanol series, and critical-point dried in a LADD critical-point drier (LADD Research Industries, Inc., Burlington, VT) using liquid $\mathrm{CO}_{2}$. The samples were sputtercoated using a sputter coater (model Kurt J. Lesker 108; 
Table 1. Gross composition (mean $\pm \mathrm{SD}$ ) on DM basis for the cheeses (moisture content $=55 \% ; P<0.05$ ).

\begin{tabular}{|c|c|c|c|c|}
\hline Sample & Fat & Protein & Lactose & Ash \\
\hline & & 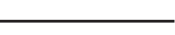 & & \\
\hline Pilot plant gritty cheese & $73.9 \pm 0.16$ & $19.3 \pm 0.48$ & $5.3 \pm 0.35$ & $1.5 \pm 0.03$ \\
\hline Commercial gritty cheese & 74.4 & $14.9 \pm 0.07$ & $3.82 \pm 0.10$ & $2.1 \pm 0.03$ \\
\hline Commercial smooth cheese & $69.3 \pm 0.70$ & $12.7 \pm 0.12$ & $7.2 \pm 1.16$ & $2.8 \pm 0.29$ \\
\hline
\end{tabular}

Clairton, PA) for $40 \mathrm{~s}$ with platinum, for an approximate thickness of $4 \mathrm{~nm}$.

Samples were viewed in a field emission scanning electron microscope (model S-4000T FESEM; Hitachi Scientific Instruments, Mountain View, CA) operated at $3 \mathrm{kV}$. Images from each sample, at $1500 \times$ magnification, from 2 fields were recorded digitally using Spectrum 2.0 software (The Dindima Group Pty. Ltd., Ringwood, Victoria. Australia). Fields were randomly selected from areas of the sample that exhibited planes of fracture of good quality.

\section{Effect of Particles on Grittiness}

The effect of particles on the perceived grittiness of cream cheese was studied using sensory evaluation. A 15-member untrained panel was used for 2 different sensory ranking tests. In the first test, samples were prepared by the addition of the particles at $0,5,15$, and $25 \%$ (wt/wt) levels to smooth cream cheese, and the panel was asked to rank them on the scale of 1 (most gritty) to 4 (least gritty). In the second ranking test, Fraction I (i.e., $\geq 150 \mu \mathrm{m})$ and Fraction $2(<150$ $\mu \mathrm{m}$ ) were added separately at 3 different levels (i.e., no particles $[0 \mathrm{~g}], 1 \mathrm{~g}$ of particles in $5 \mathrm{~g}$ of smooth cream cheese [16\%], and $2 \mathrm{~g}$ of particles in $5 \mathrm{~g}$ of smooth cream cheese [29\%]). The panelists were asked to rank the sample from 1 (most gritty) to 5 (least gritty).

All of the experiments were carried out in duplicate, and analyses were done in triplicate. The results represent the mean values for all of the samples. Statistical analyses were done using Minitab (version 13.1) software program at $95 \%$ level of confidence.

\section{RESULTS AND DISCUSSION}

The gross compositions of all 3 types of cheeses used in this study are presented in Table 1 . The protein content of the commercial cheeses was significantly lower $(P<0.05)$ than the cheese manufactured at a pilot scale. This may be explained by the presence of salt (no maximum limit indicated in the standard of identity), stabilizers, and emulsifiers (1.8\% on DM basis maximum allowed) in the commercial cheeses, which contributed approximately 4.5 to $5 \%$ on DM basis. Particles were separated using the method described earlier from the pilot scale cheese as well as commercial gritty cheese. The gross compositions of the particles isolated from both types of cheeses are shown in Table 2.

It was also found that protein content in the isolated particles (from pilot scale cheese and commercial gritty cheese) was significantly higher $(P<0.05)$ than the respective cream cheese samples. Modler et al. (1989) reported that the gritty particles were composed of compacted protein. Our findings about the particle composition help us confirm those findings. There was no significant difference $(P>0.05)$ in the fat content of the particles and the cheeses. The differences in the ash and lactose content between the particles and the cheeses might have been due to the washing procedure used for the separation of the particles. It was also found that there were no significant differences $(P>0.05)$ in the composition of the particles separated from the pilot scale cheeses as well as the commercially obtained gritty cheese. Thus, we were able to establish the similarity in composition of the particles in the pilot scale cheese and commercially made cheese.

The cheese and the particles isolated from them were analyzed for its protein profile using 15\% SDS-PAGE gels. The photograph of the gel obtained is shown in Figure 3 and the distribution is presented in Tables 3 and 4.

The main differences or contrasts between the commercial and the pilot scale gritty cheese was that $\kappa$ casein was significantly higher $(P<0.05)$ in pilot scale

Table 2. Gross composition (mean \pm SD) for the particles separated from the gritty pilot plant cheese and that obtained commercially $(P<0.05)$.

\begin{tabular}{|c|c|c|c|c|}
\hline Particles separated from & Fat & Protein & Lactose & Ash \\
\hline Pilot scale cheese & $72.6 \pm 2.12$ & $22.6 \pm 1.55$ & $4.3 \pm 0.65$ & $0.4 \pm 0.03$ \\
\hline Commercial gritty cheese & $73.8 \pm 0.77$ & $22.2 \pm 0.19$ & $2.72 \pm 0.10$ & $0.3 \pm 0.03$ \\
\hline
\end{tabular}



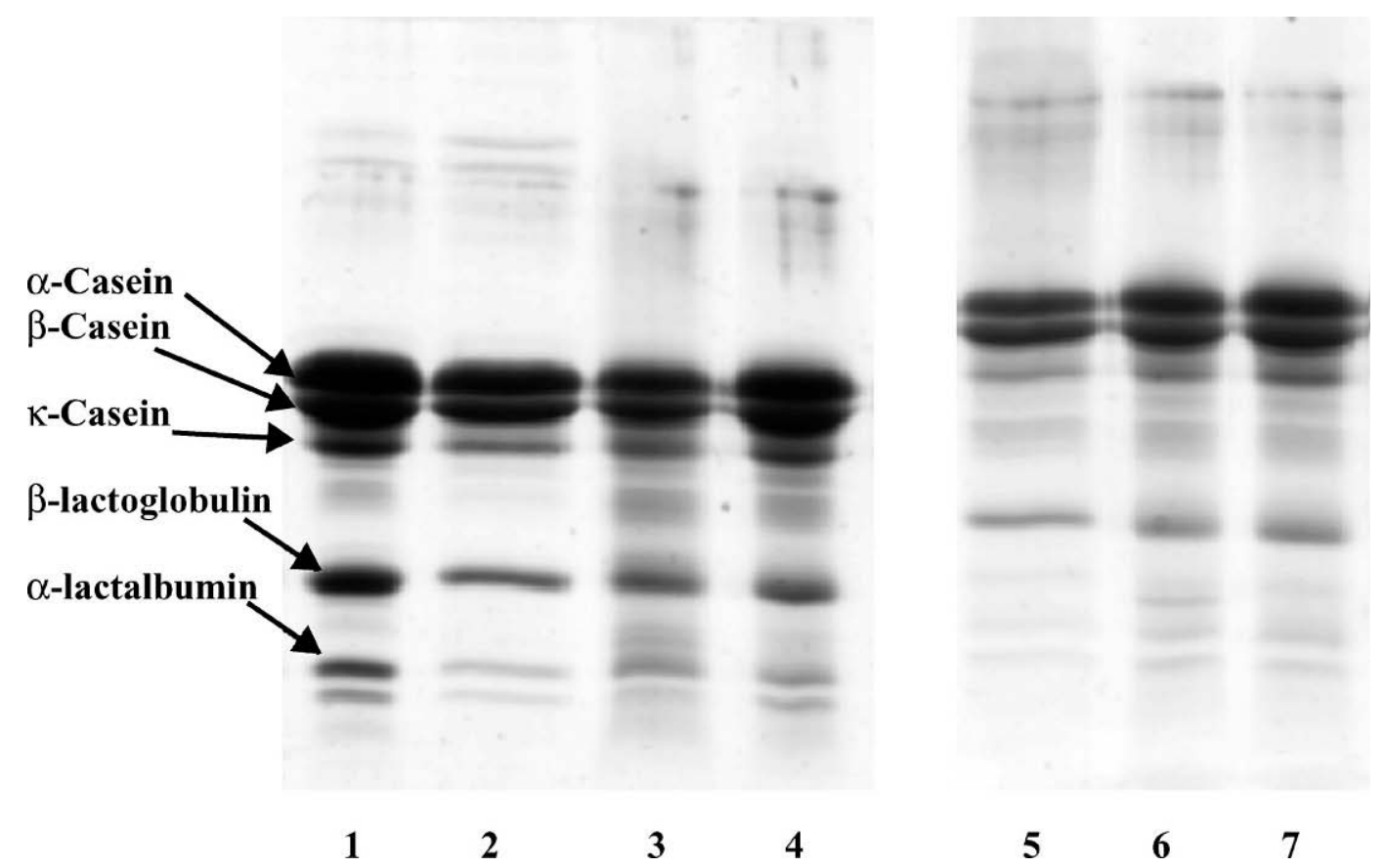

Figure 3. 15\% SDS-PAGE gel for the cheeses as well as particles. Lane 1: Commercial gritty cheese, lane 2: commercial smooth cheese, lanes 3 and 4: pilot scale gritty cheeses, lane 5: gritty particles separated from commercial gritty cheese, lanes 6 and 7: gritty particles separated from pilot scale cheeses.

cheese than in commercial gritty cheese. Gritty cheeses (commercial and pilot scale) were significantly higher $(P<0.05)$ in $\alpha$ - and $\beta$-casein fractions as compared with the smooth commercial cheese. There was no significant difference $(P>0.05)$ between the different fractions of protein in the pilot scale cheese and the particles isolated from it. However, the casein fractions $(\alpha, \beta$, and $\kappa)$ were higher, whereas the whey fractions ( $\alpha$-lactalbu$\min$ and $\alpha$-lactoglobulin) were lower in particles as compared with the cheeses. Particles occurring in the commercial gritty cheese were significantly lower $(P<0.05)$ in whey protein fractions, i.e., $\alpha$-lactoglobulin and $\beta$ lactalbumin as compared with the particles occurring in the pilot scale cheese. It was observed (Figure 3, Tables 3 and 4) that the amount of $\beta$-lactoglobulin retained in the particles as compared with $\alpha$-lactalbumin were higher. This may be due to the interaction of $\kappa$ casein and $\beta$-lactoglobulin (as reported in the literature earlier) during heating (cooking) of the curd; thus, $\beta$ lactoglobulin is more retained in the particles as compared with $\alpha$-lactalbumin.

Kalab and Modler (1985) reported the size of the particles as approximately $50 \mu \mathrm{m}$, whereas Modler et al. (1989) reported that particles ranged from 10 to 100 $\mu \mathrm{m}$ using SEM and fluorescence microscopy techniques, respectively. The particle size distribution for the particles isolated from the pilot scale cheeses and commercial gritty cheese is shown in Figure 4. The size distribution ranged from 0.04 to $850 \mu \mathrm{m}$ for both the samples, and the mean diameters were 239 and $154 \mu \mathrm{m}$ for particles from pilot scale and commercial gritty cheeses, respectively. The mean particle size in the commercial

Table 3. Quantification (mean \pm SD) using densitometer for the major fractions of protein in different cheese samples from eluted on 15\% SDS-PAGE gels.

\begin{tabular}{|c|c|c|c|c|c|}
\hline Sample & $\alpha$-Casein & $\beta$-Casein & $\kappa$-Casein & $\beta$-Lactoglobulin & $\alpha$-Lactalbumin \\
\hline & & & $-(\%)$ & & \\
\hline Commercial gritty cheese & $41.7 \pm 0.67$ & $30.9 \pm 2.19$ & $9.8 \pm 0.04$ & $9.6 \pm 0.02$ & $1.9 \pm 0.08$ \\
\hline Commercial smooth cheese & $29.3 \pm 0.47$ & $25.2 \pm 0.72$ & $11.1 \pm 0.51$ & $12.3 \pm 0.40$ & $3.9 \pm 0.51$ \\
\hline Pilot scale gritty cheese (I) & $36.2 \pm 2.64$ & $27.9 \pm 0.04$ & $11.1 \pm 0.04$ & $9.7 \pm 0.311$ & $2.7 \pm 0.59$ \\
\hline Pilot scale gritty cheese (II) & $37.6 \pm 3.07$ & $29.4 \pm 0.44$ & $11.3 \pm 0.39$ & $9.4 \pm 0.61$ & $2.5 \pm 0.87$ \\
\hline Milk $^{1}$ & 38.6 & 28.4 & 10.1 & 9.8 & 3.7 \\
\hline
\end{tabular}

${ }^{1}$ Walstra and Jenness (1984). 
Table 4. Quantification (mean \pm SD) using densitometer for the major fractions of protein for the particles eluted on $15 \%$ SDS-PAGE gels.

\begin{tabular}{|c|c|c|c|c|c|}
\hline Particles isolated from & $\alpha$-Casein & $\beta$-Casein & $\kappa$-Casein & $\beta$-Lactoglobulin & $\alpha$-Lactalbumin \\
\hline & & & $(c$ & & \\
\hline Commercial gritty cheese & $35.5 \pm 0.74$ & $32.3 \pm 1.23$ & $11.1 \pm 0.83$ & $8.1 \pm 0.21$ & $1.3 \pm 0.02$ \\
\hline Pilot scale gritty cheese $(\mathrm{I})^{1}$ & $36.8 \pm 1.65$ & $31.1 \pm 1.60$ & $10.1 \pm 0.25$ & $8.6 \pm 0.80$ & $1.5 \pm 0.12$ \\
\hline Pilot scale gritty cheese (II) & $34.6 \pm 1.78$ & $29.2 \pm 0.80$ & $12.2 \pm 0.41$ & $9.0 \pm 0.68$ & $2.1 \pm 0.13$ \\
\hline
\end{tabular}

${ }^{1}$ Fractions I and II are the replicates of the cheeses and the particles isolated from them.

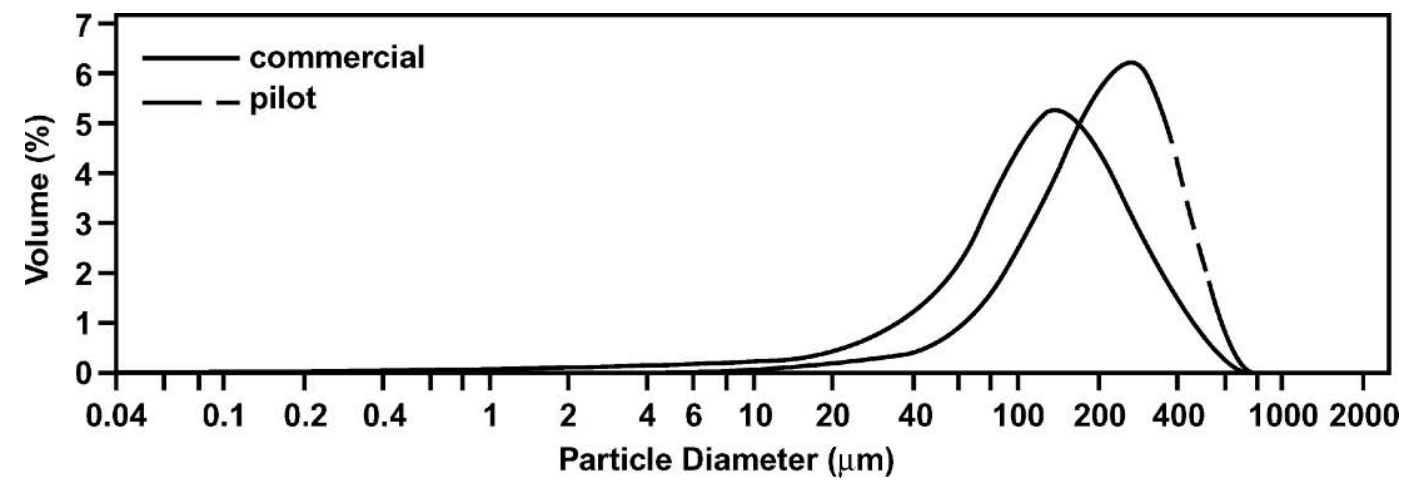

Figure 4. Particle size distribution (on volume percentage bases) for the particles separated from commercial gritty cheese and from pilot scale cheese.
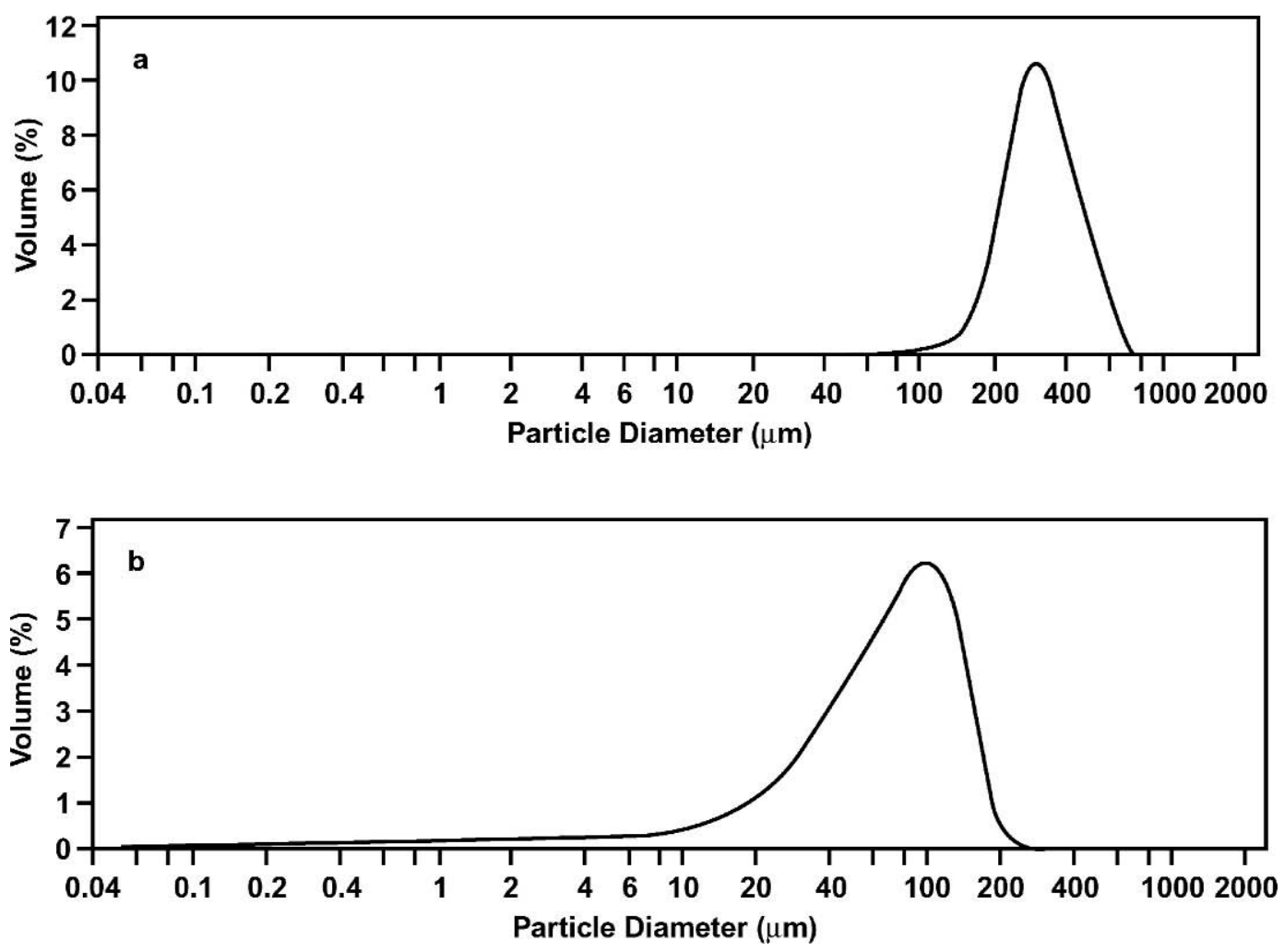

Figure 5. Particle size distribution (on volume percentage bases) for Fraction I (a) and Fraction II (b). 


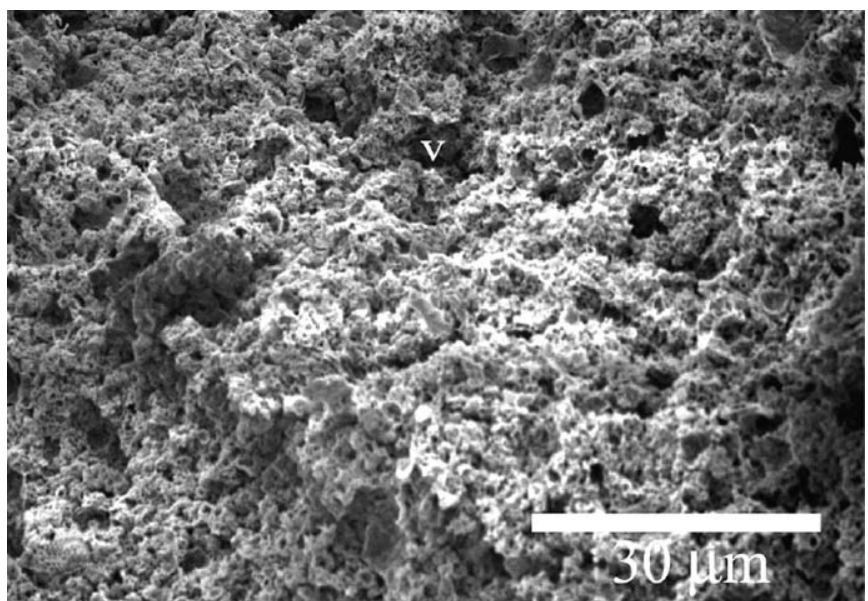

Figure 6. SEM of commercial smooth cheese at a lower magnification. Void spaces (v) result from the moisture extraction.

sample was lower than the pilot scale cheeses. This result might have been due to mechanical stirring of the curd at a high speed or homogenization of the curd, which may help in reducing the average particle size of commercial cream cheese. The particle size distribution for Fraction I and Fraction II is shown in Figure 5. The distribution ranged from 1 to $850 \mu \mathrm{m}$ for Fraction I, with a mean diameter of $322 \mu \mathrm{m}$, whereas the distribution for Fraction II ranged from 0.04 to $250 \mu \mathrm{m}$, with a mean particle size diameter of $79 \mu \mathrm{m}$. These fractions were later used for the sensory analysis. Fraction I particles were filtered using the $150-\mu \mathrm{m}$ mesh filter. Smaller particles might have attached to the larger size particles and, thus, were retained. Some of the larger-sized particles may be able to pass through the filter because

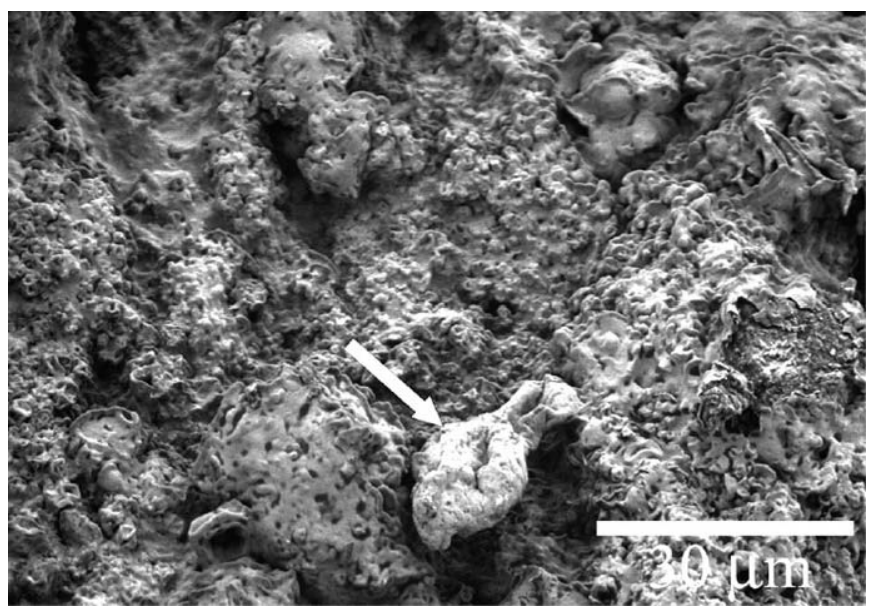

Figure 7. SEM micrograph for gritty cheese manufactured at pilot scale. Light arrow points to the compacted protein.

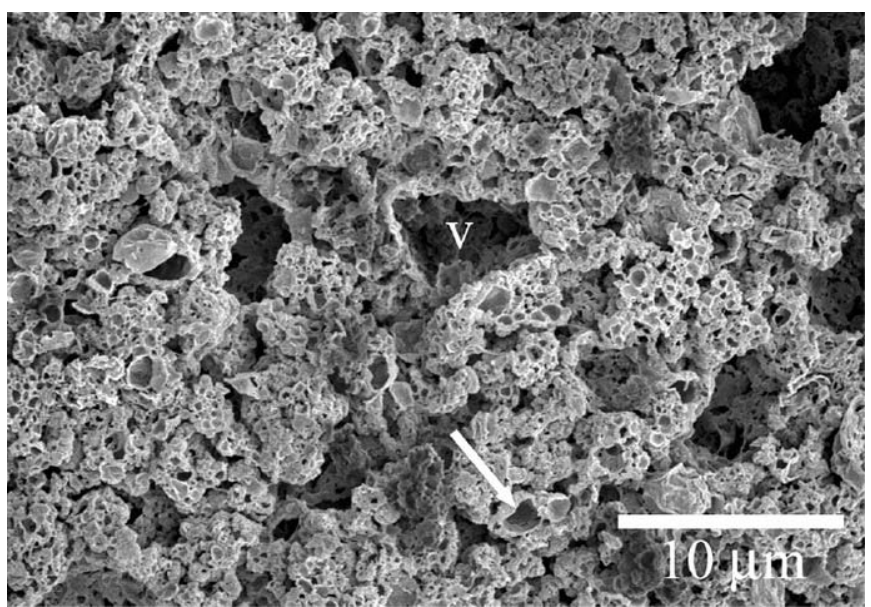

Figure 8. Details for the microstructure for the commercial smooth cheese. Light arrow points to the void created by the extraction of fat and void spaces (v) from the moisture extraction.

of their irregular shape and, thus, ended up in Fraction II, which may help to explain the overlapping of the 2 fractions.

Scanning electron microscopy revealed that the smooth cheese had relatively uniform protein matrices (Figure 6), where void space created by moisture extraction is shown by ' $v$ ' in the figure. It was found that the cheese consisted of fat globules uniformly dispersed in protein matrix. In contrast, the gritty sample had a coarse structure with compacted protein, which was visible even at lower magnification (Figures 7 and 8). These particles ('p' as represented in the figure) were looked at in greater detail as shown in Figure 9. The particles seem to be embedded in the protein matrix. This matrix seems to be similar to the protein matrix observed in smooth cheese, where fat globules were uniformly dispersed throughout the network. The particle shapes varied from being elongated, near spherical, to irregular (Figures 10 and 11).

\section{Effect of Particles on the Grittiness of Cheese}

In the first sensory experiment, where a 15-member panel was asked to rank the samples from most gritty (rank 1) to least gritty (rank 4), the sample with $25 \%$ of the gritty particles added was perceived as the most gritty, and the ranks follow the linear pattern with decrease in the amount of particles added. The results of this study are shown in Figure 12. Interestingly, smooth cream cheese with particles added only at the $5 \%$ level was perceived as gritty. In another ranking test (where size as well as amount of particles was varied), panelists were asked to rank the samples from most gritty (rank 1) to least gritty (rank 5 ). The results 

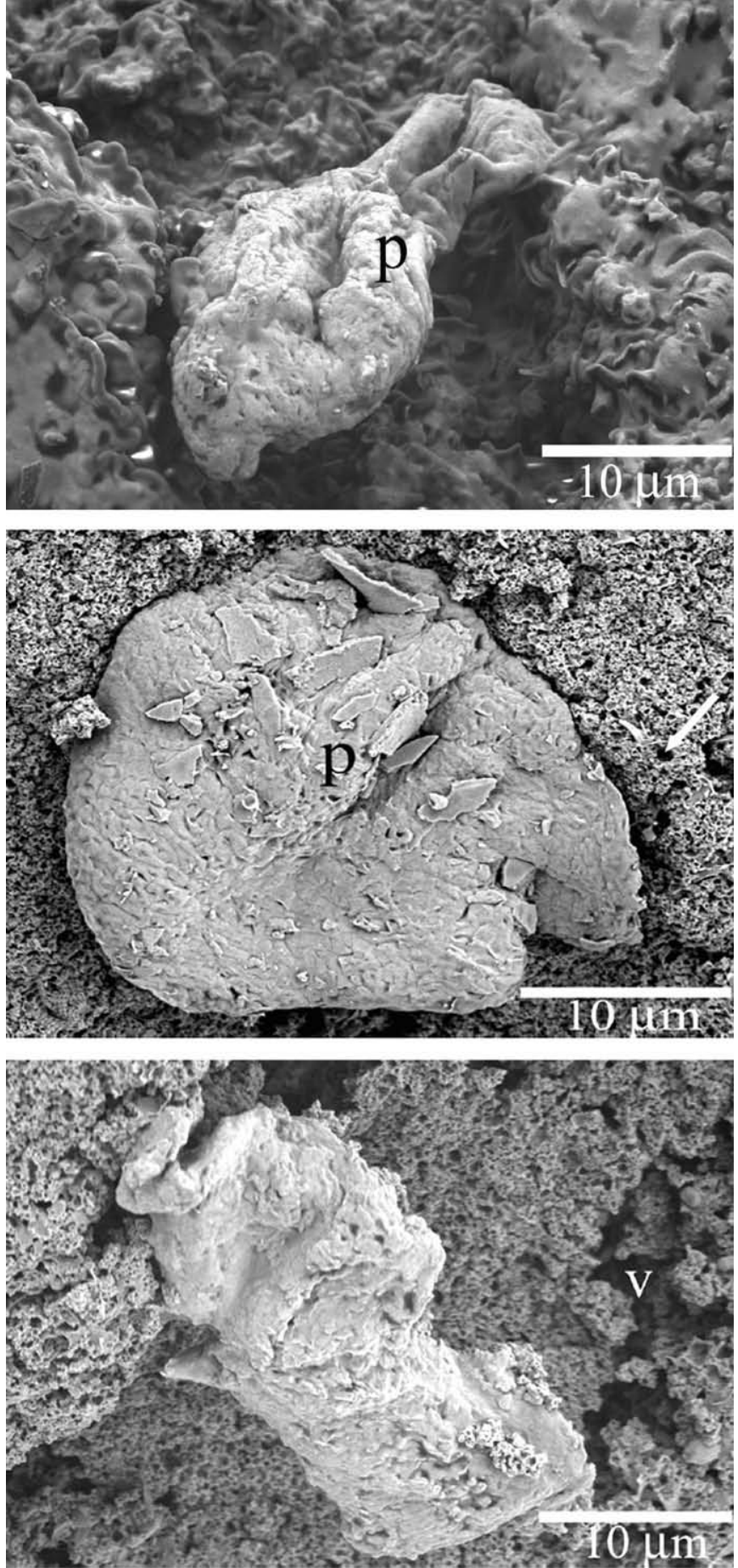

Figure 9. Details of the morphology of the compact particles (p) present in the gritty cheese. Void spaces (v) result from the moisture extraction, and light arrow points to the void created by the extraction of fat.

of this set of experiments are shown in Figure 13. Results show that size and amount of the particles added had a significant effect on the perceived grittiness in

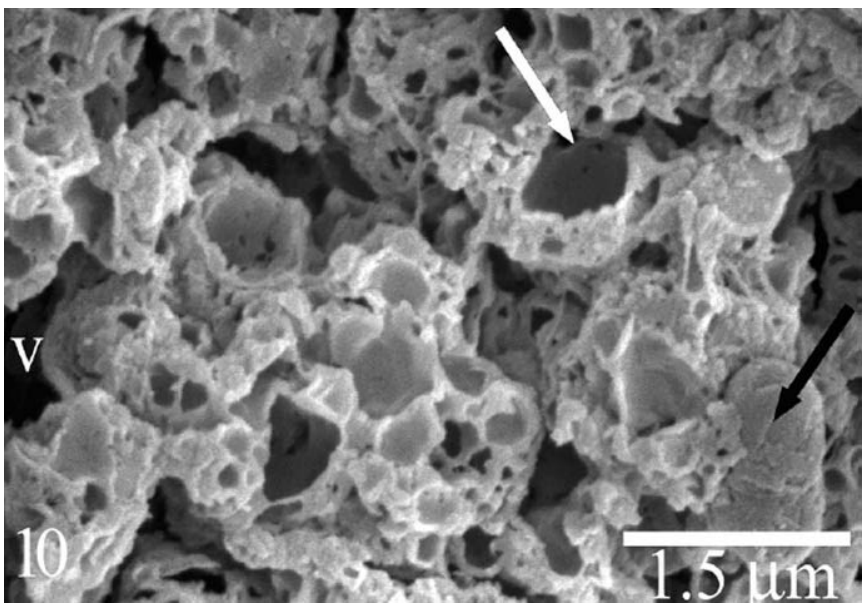

Figure 10. Details for the microstructure for the commercial smooth cheese. Light arrow points to the void created by the extraction of fat and dark arrow towards the microorganism.

the cheese. As the size and amount of particles increased, the mean ranks for perceived grittiness decreased. This shows that the cheese was perceived to be grittier with an increase in amount and size of the particles, which further indicates a low threshold $(<5 \%)$ for significant grainy perception.

\section{CONCLUSIONS}

A method for the isolation of particles from cream cheese was developed. The particles had significantly higher protein concentration compared with the source cheeses. The particles isolated for the pilot scale gritty cheeses were almost identical to the particles isolated from the commercial gritty cheese in their composition,

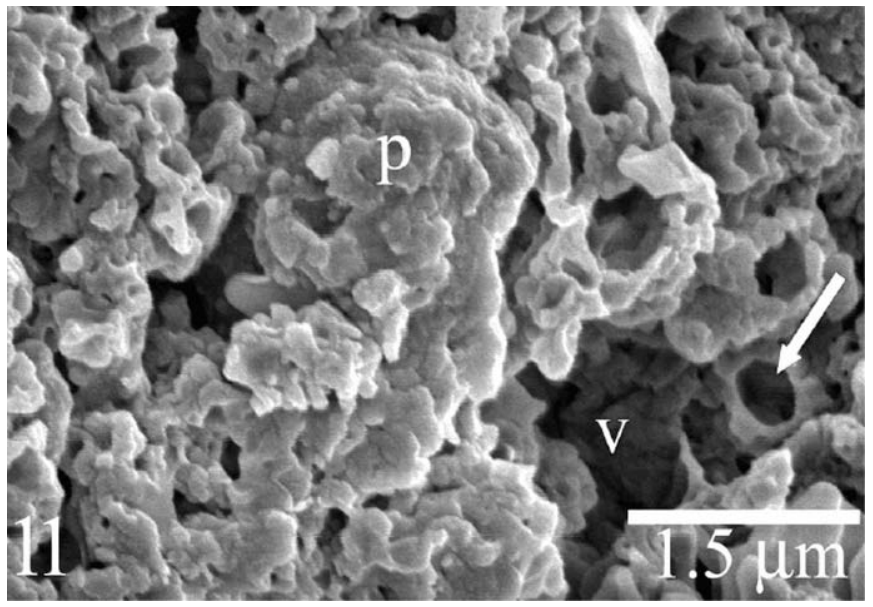

Figure 11. Detail of the compact particle (p) present in the gritty cheese made at pilot scale. 


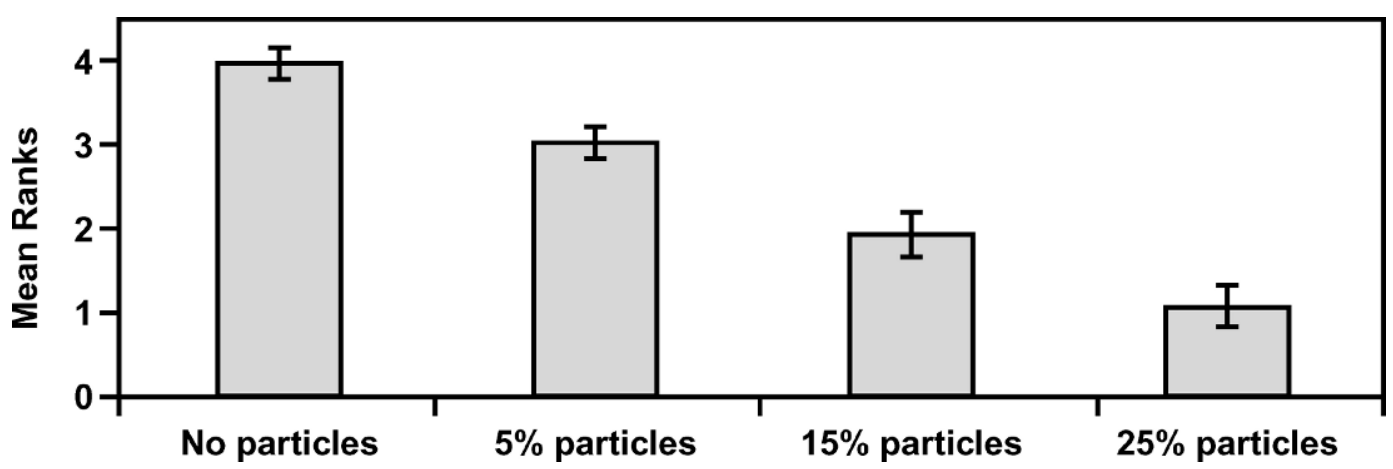

Figure 12. Average ranks for the samples with added particles $(5,15$, and $25 \%)$, where $4=$ least gritty and $1=$ most gritty.

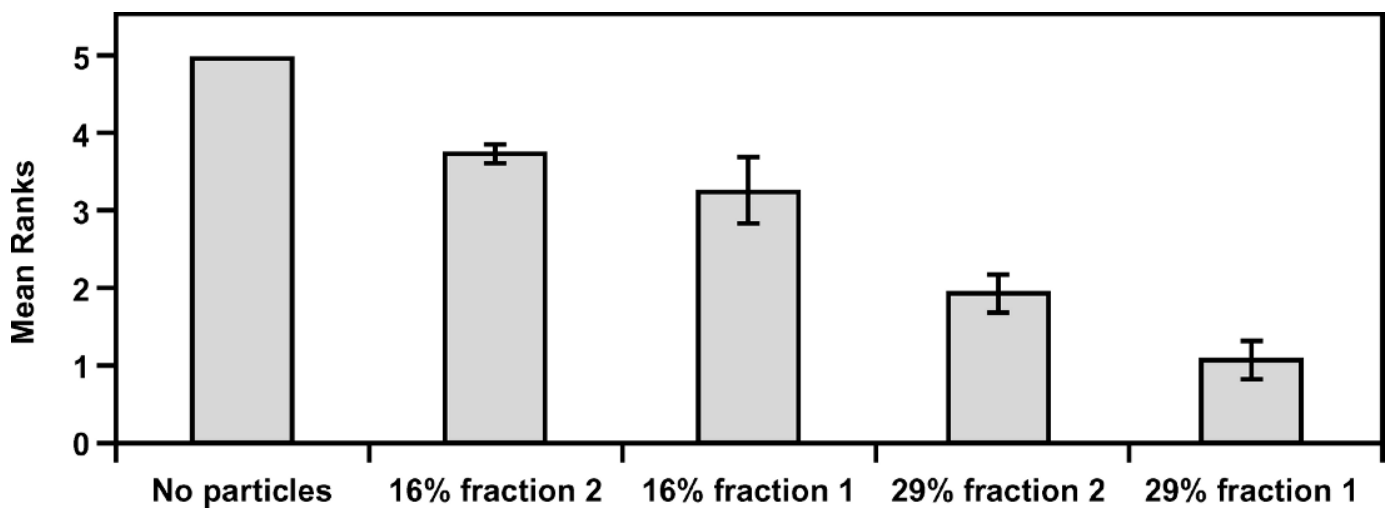

Figure 13. Average ranks for the samples with added particles ( 16 and $29 \%$; fraction 1 and fraction 2$)$, where $5=$ least gritty and $1=$ most gritty.

protein profile, and sizes. Perceived grittiness of cream cheese increases with greater amounts and larger size of the added particles. Subsequent work may be done to get a more detailed understanding of the factors that influence the formation of the particles that contribute to grittiness or graininess and to evaluate conditions that would reduce the perceived grittiness by studying the effects of different processing parameters on grittiness in cream cheese.

\section{ACKNOWLEDGMENTS}

The authors acknowledge Bonney Sam Oommen at the Department of Nutrition and Food Science, Utah State University, Logan, for assisting with electron microscopy work. We appreciate the help by Sean Vink at the Dairy Products Technology Center, Cal Poly State University, San Luis Obispo, in the manufacturing of the pilot scale cream cheese. We thank Dairy Management Inc. and California Dairy Research Foundation for financial support.

\section{REFERENCES}

Association of Official Analytical Chemists. 2000. Official Methods of Analysis. Vol. II. 17th ed. AOAC, Gaithersburg, MD.

Goers, J. 1993. Immunochemical Techniques, Laboratory Manual. Academic Press, San Diego, CA.

Harwalkar, V. R., and M. Kalab. 1980. Milk gel structure. XI. Electron microscopy pf glucono- $\delta$-lactone induced skim milk gels. J. Texture Stud. 11:35-49.

Harwalkar, V. R., and M. Kalab. 1981. Effect of acidulants and temperature on microstructure, firmness and susceptibility to syneresis of skim milk gels. Scan. Electron Microsc. 3:503-513.

International Dairy Foods Association. 2001. Cheese Facts. IDFA, Washington, DC.

Kalab, M., D. B. Emmons, and A. G. Sangant. 1975. Milk gels structure IV. Microstructure of yoghurts in relation to the presence of thickening agents. J. Dairy Res. 42:453-458.

Kalab, M., and H. W. Modler. 1985. Development of microstructure in cream cheese based on Queso Blanco cheese. Food Microstruct. 4:89-98.

Kalab, M., A. G. Sargant, and D. A. Froehlich. 1981. Electron microscopy and sensory evaluation of commercial cream cheese. Scan. Electron Microsc. 3:473-482.

Kleyn, D. H., and J. R. Trout. 1984. Enzymatic-ultraviolet method for measuring lactose in milk: Collaborative study. J. AOAC 67:637-640.

Lucey, J. A., P. A. Munro, and H. Singh. 1998. Effect of heat treatment and whey protein addition on rheological properties and structure of acid skim milk gels. Int. Dairy J. 9:275-279. 
McManus, W. R., D. J. McMahon, and C. J. Oberge. 1993. Highresolution scanning electron microscopy of milk products: A new sample preparation procedure. Food Struct. 12:475-482.

Modler, H. W., S. H. Yiu, U. K. Bollinger, and M. Kalab. 1989. Detection and prevention of grittiness in a cream cheese spread. Posters and Brief Communications of XXIII Int. Dairy Congr., Montreal, Canada. Int. Dairy Fed., Brussels, Belgium.

Modler, H. W., S. H. Yiu, U. K. Bollinger, and M. Kalab. 1990. Grittiness in pasteurized cheese spread: A microscopic study. Food Microstruct. 8:201-210.

Mulvihill, D. M., and M. Donovan. 1987. Whey proteins and their thermal denaturation-A review. Ir. J. Food Sci.Technol. 11:43-75.

Mulvihill, D. M., and M. B. Grufferty. 1995. Effect of thermal processing on coagulability of milk by acid. Pages 118-205 in Heat
Induced Changes in Milk, 2nd ed. International Dairy Federation Special Issue no. 9501. P. F. Fox, ed. IDF, Brussels, Belgium.

Sanchez, C., J. L. Beauregard, M. Bride, W. Buchheim, and J. Hardy. 1996. Rhelogy and microstructural characterization of double cream cheese. Nahrung 40:108-116.

Singh, H., and L. K. Creamer. 1992. Heat stability of milk. Pages 621-656 in Advanced Dairy Chemistry. 1. Proteins. P. F. Fox, ed. Elsevier Appl. Sci., London, UK.

Walstra, P., and R. Jenness. 1984. Dairy Chemistry and Physics. John Wiley \& Sons, New York, NY.

Xiong, Y. L., and J. E. Kinsella. 1991. Influence of fat globule membrane and composition and fat type on the rheological properties of milk fat based composite gels II. Results. Milchwissenschaft 46:207-212.

Zhu, H., and S. Damodaran. 1994. Heat-induced conformational changes in whey protein isolate and its relation to foaming properties. J. Agric. Food Chem. 42:846-855. 